\title{
DossIIE
}

Natanael Gomide Junior ${ }^{1}$

\section{MERCOSUL SOCIAL E PARTICIPATIVO: UMA REVISÃO DAS NORMATIVAS E INSTÂNCIAS CRIADAS}

\author{
SOCIAL AND PARTICIPATORY MERCOSUR: A REVIEW OF THE NORMATIVE AND \\ INSTANCES CREATED
}

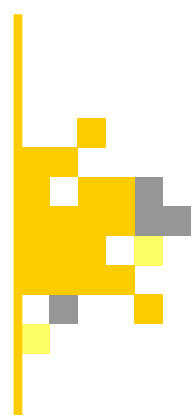

\section{RESUMO:}

No início dos anos 2000, as consequências econômicas do neoliberalismo, associadas a uma "virada à esquerda" nos governos sul-americanos, proporcionou que questões sociais e políticas ganhassem protagonismo na agenda política regional do Mercosul em detrimento dos assuntos meramente comerciais, tema que pautou o despertar do bloco regional. Para incorporar as novas questões, como os direitos sociais, direitos humanos e a participação social, inúmeras normativas e instâncias foram criadas. $\mathrm{O}$ objetivo deste artigo é realizar uma revisão sobre as principais normativas e instâncias criadas, com enfoque especial para a questão participativa. Para atingir a este objetivo, recorremos à revisão bibliográfica da literatura especializada e à análise documental. A partir da análise, podemos identificar que o Mercosul trilhou relativamente um curto caminho na implementação de mecanismos participativos para atores não-estatais, já que inúmeros órgãos e instâncias contam com mecanismos participativos institucionalizados, não obstante, as críticas e as necessidades de aperfeiçoamento.

Palavras-Chave: Mercosul; Agenda Social; Participação Social.

\section{ABStRACT:}

In the early 2000s, the economic consequences of neoliberalism, associated with a "left-wing turn" in South American governments, allowed that social and political issues to gain prominence in Mercosur's regional political agenda to the detriment of purely commercial issues, a theme that guided the awakening of the regional bloc. To incorporate new issues, such as social rights, human rights and social participation, numerous normative and instances were created. The aim of this article is to do a review of the main normative and created instances, with a special focus on the participatory issue. To achieve this goal, we resorted to literature review and documentary analysis. From the analysis, we can identify that Mercosur has taken a relatively short path in the implementation of participatory mechanisms for non-state actors, since numerous bodies and instances have institutionalized participatory mechanisms, despite criticism and needs for improvement.

KeYwords: Mercosur; Social Agenda; Social Participation.

\section{INTRODUÇÃO}

O Mercosul, um processo de integração regional firmado em 1991 por Argentina, Brasil, Paraguai e Uruguai, tinha como primazia a facilitação das trocas e bens comerciais entre estes países. O objetivo primordial do bloco regional era a eliminação de tarifas e restrições aduaneiras, facilitando o livre comércio entre os países do bloco.
Esse modelo, fortemente marcado pelo viés econômico e comercial, começa a sucumbir a partir de uma "virada à esquerda" nos governos regionais no início dos anos 2000. Desde então, a agenda social e política ganhou cada vez mais espaço na estrutura institucional do Mercosul, em detrimento dos assuntos meramente econômicos

\footnotetext{
${ }^{1}$ Mestre em Relações Internacionais pela Universidade Federal de Uberlândia (UFU) . natanaelgomidejunior@gmail.com (iD) https://orcid.org/0000-0003-1399-9928
} 
e comerciais. Para tratar destas novas questões participação social, direitos sociais e humanos foram paulatinamente sendo criadas normativas, políticas e instâncias.

O objetivo deste artigo é realizar uma revisão bibliográfica sobre as principais normativas e instâncias criadas nos anos 2000 para tratar da nova agenda no Mercosul, com enfoque para a questão participativa. Para atingir este objetivo, recorremos à revisão bibliográfica da literatura especializada, com vistas a compreender o cenário da emergência de uma nova agenda política na integração regional do Mercosul. Como subsídio para entender a criação de novas normativas e instâncias no seio do Mercosul a partir da década de 2000, recorremos à análise documental primária de arquivos disponíveis no website do Mercosul.

Organizamos este artigo em três seções. $\mathrm{Na}$ primeira, realizamos um breve remonte histórico sobre os regionalismos nas Américas, salientando o contexto de criação do Mercosul. Na segunda seção, discorremos sobre a guinada na agenda política regional, em que os assuntos sociais e políticos adquirem uma nova e importante tônica. Na terceira seção, dissertamos sobre a questão participativa no Mercosul, elencando como esta questão tem sido tratada, as dificuldades e os avanços alcançados no decorrer histórico.

\section{REGIONALISMO NAS AMÉRICAS}

A primeira tentativa de integração regional no continente latino-americano pode ser atribuída às ideias de Simón Bolívar, um político e líder militar venezuelano. Apesar da linguagem e religião em comum, e da cultura compartilhada, fatores divisionários prevaleceram na região. A falha da tentativa de integração conduziu a um panamericanismo, uma noção soft de união continental para o gerenciamento das relações internacionais latino-americanas. Depois da II Guerra Mundial, a ênfase mudou de união política para integração econômica. Entre os fatores responsáveis por essa virada estão o argumento funcional de que as organizações internacionais poderiam servir meIhor para arranjos nos relacionamentos econômicos, sociais e culturais ao invés de integração federal ou política (MALAMUD, 2010).

Neste cenário do pós-II Guerra Mundial, surgem na América Latina, alguns processos de integração regional, como a Associação Latinoamericana de Livre Comércio (ALALC), mais tarde renomeada para Associação de Integração Latinoamericana; o Mercado Comum Centro-americano e a Comunidade Andina (MALAMUD, 2010).

$\mathrm{Na}$ década de 1990, o regionalismo ganha um novo fôlego, com novos acordos regionais sendo instituídos na África, Ásia e nas Américas. É dentro deste cenário que se insere a criação do Mercado Comum do Sul (Mercosul).

O início da cooperação regional no Cone Sul se dá em 1985 a partir da aproximação entre Argentina e Brasil, durante seus esforços de redemocratização. Nesse momento, os parlamentares nacionais estavam debruçados sob os assuntos internos de seus respectivos países, entendendo a estratégia de aproximação dos dois países como uma estratégia de política externa dos executivos nacionais. Dessa forma, segundo Mariano (2011), o Congresso brasileiro dedicou pouca atenção neste alvorecer do processo de integração regional, visto que estava preocupado com o processo constituinte doméstico. Do lado argentino, também havia a preocupação com a questão democrática e com a estagnação econômica. Os parlamentos somente dedicaram atenção à integração regional a partir do Tratado de Integração Cooperação e Desenvolvimento entre Argentina e Brasil, instituído em 1988, na qual foi estabelecido o Programa de Integração e Cooperação Econômica (PICE) e a Comissão Parlamentar Conjunta de Integração (CPCI).

O Mercosul é um processo de integração regional instituído por meio do Tratado de Assunção, firmado em 26 de março de 1991, inicialmente entre Argentina, Brasil, Paraguai e Uruguai. Posteriormente, a Venezuela $(2006)^{2}$ foi outro país a ser incorporado ao bloco regional. O bloco regional possuía como objetivo principal, conforme

\footnotetext{
${ }^{2}$ No momento, o país se encontra suspenso de suas obrigações e deveres enquanto Estado Parte, medida esta que evoca ao Tratado de Ushuaia sobre compromisso democrático.
} 
enunciado no artigo primeiro do Tratado de Assunção, à livre circulação de bens, serviços e fatores produtivos entre os países, através da eliminação de direitos aduaneiros e de restrições a livre circulação de mercadorias. O Tratado também previa a criação de uma tarifa externa comum para facilitar as trocas comerciais entre os Estados.

Diante do exposto, podemos visualizar que este processo de integração regional possui inicialmente uma proeminência de caráter comercial. Em outras palavras, o processo de integração regional sulamericano tinha o objetivo de facilitar as trocas comerciais entre os países da região. Esse fenômeno, em convergência com outros acordos regionais firmados nos anos 1990 e a primeira década do século XXI, foi caracterizado como 'regionalismo aberto' (SERBIN, 2012a; 2013; MATTLI, 2012; MALAMUD, 2013). O termo "aberto" significa que os acordos regionais instituídos neste momento davam primazia à liberalização econômica e se pautavam por reformas pró-mercado. As políticas competitivas se tornaram o cerne dos processos de integração regional na Comunidade Andina, NAFTA e no Mercosul (SERBIN, 2012a; 2013).

Segundo Natera (2016), o Mercosul emerge em um contexto de hegemonia político-cultural do Consenso de Washington (1989), na qual o crescimento econômico passava necessariamente pela desregulação financeira e pela privatização. Em outras palavras, segundo o autor, essas políticas significam o desmonte do Estado nacional-popular construído mediante lutas sociais e políticas desde o fim da II Guerra Mundial.

Tendo em vista a ênfase comercial em sua concepção, dois grupos privados disputaram com os Estados as negociações do processo de integração regional, os empresários e os sindicatos. Vigevani (1996) define três momentos da posição dos sindicatos frente ao processo de integração regional no Mercosul. A primeira se inicia com os acordos de Alfonsín-Sarney de 1986 até o Tratado de Assunção de 1991. Nesta fase, em geral, as centrais sindicais são favoráveis à integração regional como uma forma de cooperação econômica, porém críticas quanto à ausência de questões sociais na pauta da integração. Nesse período, há uma forte atividade da
Coordenadoria de Centrais Sindicais do Cone Sul (CCSCS) enquanto fórum de debate.

A segunda fase corresponderia aos anos de 1991 e 1992, quando as centrais sindicais passam a ser incorporadas formalmente aos grupos de trabalhos SGT-11 (Relações Trabalhistas, Emprego e Seguridade Social); SGT-7 (Política Industrial e Tecnológica) e SGT-8 (Política Agrícola). Nesta fase, as centrais sindicais possuem uma atitude mais defensiva de desconfiança frente aos rumos tomados no processo integracionista. A terceira fase, iniciada em 1993, corresponde a uma atuação mais ativa do sindicalismo, particularmente da Central única de Trabalhadores (CUT) e do PIT-CNT, Uruguai (VIGEVANI, 1996).

Ainda segundo Vigevani (1996), nestas três fases, a atuação das centrais sindicais dos países do Mercosul se deu em dois planos, primeiramente como sindicatos que atuam no âmbito de seus respectivos Estados nacionais; e segundamente enquanto membros da Coordenadora das Centrais Sindicais do Cone Sul (CCSCS). Neste segundo plano, para o autor, as centrais sindicais começaram a lidar com exigências com as quais não estavam acostumadas. Durante este momento, as centrais sindicais percebem que necessitam participar do Mercosul, sendo obrigadas a elaborar uma estratégia para exercer influência diante do processo de integração. Estas possuíam uma percepção de que a integração regional era irreversível e de que teria impactos profundos sobre os países participantes. Como contrapartida, as centrais sindicais possuíam um "projeto bolivariano" que unisse economicamente, socialmente e culturalmente a América Latina. De acordo com o autor, este projeto bolivariano pode ser tratado como um incentivo simbólico à participação dos sindicatos na integração regional.

Apesar da participação da classe sindical no processo de integração regional, o Mercosul, em sua primeira normativa - o Tratado de Assunção - não possui nenhum mecanismo que prevê a participação de atores não-estatais. Dessa forma, o acordo regional é, até então, de caráter puramente intergovernamental. Foi somente em 1994, com a assinatura do Proto- 
colo adicional de Ouro Preto, o qual estabelece a estrutura institucional do Mercosul, que foram criados os primeiros espaços institucionais de participação social, por meio da Comissão Parlamentar Conjunta (CPC) e do Foro Consultivo Econômico e Social (FCES) (MARTINS, 2014; MARTINS; SILVA, 2011).

A Comissão Parlamentar Conjunta (CPC) foi criada enquanto órgão de representação dos Parlamentos dos Estados Partes. Já o Foro Consultivo Econômico e Social (FCES) se constitui enquanto órgão de representação dos setores econômicos e sociais. Possui natureza consultiva e se manifesta por meio de recomendações ao Grupo do Mercado Comum (GMC) (MERCOSUL, 1994). Segundo Martins (2014), dado o caráter intergovernamental do Mercosul, este Foro não conseguiu se consolidar, fazendo com que perdesse sua força paulatinamente. Além do mais, as organizações sociais e movimentos populares não se sentiam representados pelo FCES. Apesar dessas dificuldades, as centrais sindicais conquistaram avanços importantes, como o reconhecimento da importância dos direitos trabalhistas. A Declaração Socio laboral e o Acordo Multilateral de Seguridade Social se constituem enquanto exemplos dessas conquistas.

Apesar do crescimento econômico, a ênfase neoliberal do processo de integração regional começa a sucumbir gradativamente em razão das consequências econômicas e sociais causados pelas reformas liberalizantes, como o aprofundamento da desigualdade social, da pobreza e da exclusão social. Até instituições financeiras internacionais reconheceram as limitações deste modelo, como o Banco Interamericano de Desenvolvimento (BID) e o Banco Mundial, que alertaram quanto à necessidade de políticas visando à diminuição da distribuição desigual da riqueza na região (SERBIN, 2013).

\section{A NOVA AGENDA SOCIAL E POLÍTI- CA NO MERCOSUL}

Diante desta crise, na primeira década do século XXI, uma nova agenda começa a emergir na integração regional mercosulina. Nesta nova agenda, a dimensão social e política ganha uma nova tônica (MARTINS, 2014; NATERA, 2016; MARIANO,
2011; SERBIN, 2012a; RAMANZINI JÚNIOR, 2015). É convergente entre estes autores - e da literatura especializada em geral - que as mudanças da pauta integracionista se devem à emergência de governos de esquerda e centro-esquerda que emergem no Cone Sul. Entre estes, Tabaré Vasques e José Mujica no Uruguai; Nestor e Cristina Kirchner, na Argentina; Luiz Inácio Lula da Silva e Dilma Rousseff, no Brasil; Hugo Chávez, na Venezuela e Fernando Lugo no Paraguai. Segundo Ramanzini Júnior (2015), as mudanças iniciadas nos anos 2000, no Mercosul, são frutos de mudanças ocorridas nas estruturas políticas internas dos países membros.

Essa nova fase do regionalismo marca uma repolitização da agenda e um deslocamento de questões econômicas e comerciais para questões mais políticas, o que Serbin (2012a) caracteriza como um "retorno à política" e um "retorno do Estado" à frente das políticas sociais e de desenvolvimento. Alguns autores conceituam esse novo momento como "regionalismo pós-hegemônico" (RIGGIROZZl; TUSSIE, 2012; GRUGEL; RIGGIROZZI, 2009; RIGGIROZI, 2012) ou "regionalismo pós-liberal” (SANAHUJA, 2010).

De acordo com Sanahuja (2010), o regionalismo pós-liberal é expressão da rejeição latinoamericana às políticas neoliberais do Consenso de Washington. Tais políticas causaram um enfraquecimento da atuação estatal na promoção do desenvolvimento. Diante disso, na visão dos governos de centro-esquerda e esquerda que emergiram neste período, esta reorientação da agenda política integracionista deveria ser fundamentada em uma estratégia baseada no retorno a um Estado forte.

Resumidamente, o regionalismo pós-liberal seria caracterizado pela primazia da agenda política em detrimento da agenda econômica e comercial; um retorno da agenda de desenvolvimento; um maior protagonismo dos atores estatais, diante dos atores privados e das forças do mercado; uma ênfase maior na agenda "positiva" da integração, com a criação de instituições e políticas comuns e uma maior cooperação em temas não comerciais; maior preocupação pelas dimensões sociais e uma busca pela justiça social; ênfase na seguridade energética e na questão infra estrutural; a busca por promover uma maior participação e legitimação social dos processos de integração. 
Segundo Riggirozzi (2012), o regionalismo pósliberal faz parte de um complexo de ideias alternativas e novas motivações políticas na América Latina, no qual há um redescobrimento do espaço regional enquanto espaço de discussão e ação coletiva:

\begin{abstract}
América del Sur se perfila desde el principio de los 2000 como un área capaz de desafiar la hegemonía tradicional y la importancia que EE.UU. ha tenido como poder 'regionalizador'. La década que se abre dio a luz un debate que se centra en la búsqueda de una nueva síntesis entre el Estado y la sociedad, y entre Estado y mercado, superando los costos del neoliberalismo en términos de ciudadanía, la democracia, y la inclusión. La relación entre el Estado y el mercado, y el lugar de los actores sociales en esta relación, sin embargo, no es nueva. Ha estado en el centro del debate sobre que constituye desarrollo e integración desde finales del Siglo XIX (RIGGIROZZI, 2012, p. 134).
\end{abstract}

Emerge também nesse momento as ideias de "irmandade dos povos" e de destino comum (MARIANO, 2011) em oposição às políticas neoliberais e à instituição da Área de Livre Comércio das Américas (ALCA), vistas como extensão da influência dos EUA sob a região. Neste momento, observa-se também um aumento da capacidade de redes regionais da sociedade civil de formularem e implementarem uma agenda propositiva. Exemplos dessas redes são a Aliança Social Continental; a Mesa de Articulação de Associações e Redes de Organizações Não-governamentais da América Latina e do Caribe; o Fórum da Diplomacia Cidadã; o Congresso Bolivariano dos Povos (SERBIN, 2013).

Dentro deste novo cenário integracionista, há uma nova maneira de enxergar a resolução dos problemas sociais, por meio da ênfase em políticas sociais, pautadas pela proteção e promoção social (MARTINS, 2014). Diante disso, uma série de normativas, documentos e posteriormente instituições e instâncias são criadas para incorporar a pauta social na integração regional.

Uma das primeiras iniciativas dentro desse cenário é a criação da Reunião de Ministros e Autoridades de Desenvolvimento Social do Mercosul (RMADS), em 2000, por meio da decisão 61/00 do Conselho do Mercado Comum (CMC). A criação da
RMADS, segundo esta decisão, dá-se pela importância de ampliar e aprofundar a temática do desenvolvimento social no processo de integração regional. A RMADS tem a função de propor, por meio do Grupo Mercado Comum (GMC), medidas referentes à coordenação de políticas e o aumento de ações conjuntas voltadas ao desenvolvimento social dos Estados-Partes. Nos dois primeiros anos, segundo Martins (2014), a RMADS possuiu pouca visibilidade. No entanto, em 2005, com a criação do "Mercosul Social", no âmbito da RMADS, as ações na área social tiveram um aclive.

O Mercosul Social foi pensado inicialmente durante a VIII RMADS (Ata 01/05). Durante esta reunião, as autoridades participantes concordaram que a RMADS oferecia uma oportunidade para fortalecer os esforços no que tange à problemática social, com o objetivo de potencializar a cooperação horizontal e o intercâmbio de experiências, no desenho e implementação de políticas sociais. Dessa forma, decidiu-se pela necessidade da elaboração de um plano bienal que contém três níveis que se conectam, entre estes, a adoção de um marco conceitual e metodológico para o Mercosul Social.

Outra importante normativa aprovada é a "Declaração de Princípios do Mercosul Social", durante a XIII RMADS em 2007. Esta Declaração é fruto do compromisso assumido em 2005, pelo Mercosul na luta contra a pobreza, em que se estabelece que a consolidação da democracia depende da construção de sociedades mais equitativas e justas. Diante disso, estabelece que o núcleo familiar se constitui enquanto eixo privilegiado da intervenção das políticas sociais; do entrelaçamento entre as políticas econômicas e sociais; da proteção e promoção social enquanto eixo das políticas públicas; a importância da seguridade nutricional e alimentar; o respeito pelas particularidades territoriais e a importância do diálogo com a sociedade civil como eixo fundamental de trabalho do Mercosul Social.

Uma importante instância criada neste cenário de incorporação das temáticas sociais na pauta integracionista é o Instituto Social do Mercosul (ISM), criado em 2007 por meio da decisão 3/07 do CMC. Sua criação, de acordo com esta de- 
cisão, tem o objetivo de desenvolver a dimensão social no Mercosul, fortalecer o processo de integração e promover o desenvolvimento humano integral. Entre seus objetivos estão: contribuir para a consolidação da dimensão social como eixo fundamental do Mercosul; contribuir para a superação de assimetrias; colaborar tecnicamente no desenho de políticas sociais regionais; sistematizar e atualizar indicadores sociais regionais; coletar e intercambiar boas práticas em matéria social; promover mecanismos de cooperação horizontal e identificar fontes de financiamento.

Outro órgão criado foi a Comissão de Coordenação de Ministros de Assuntos Sociais do Mercosul (CCMASM), em 2008, por meio da decisão 39/08 do CMC: "Una de las funciones más relevantes asignadas a esta dependencia en la estructura organizacional del MERCOSUR consiste en supervisar la correcta ejecución de los proyectos sociales regionales aprobados por el CMC" (INSTITUTO SOCIAL DO MERCOSUL, 2019, on-line). Além disso, entre suas funções estão: elevar propostas de trabalho relativas ao plano estratégico de ação social do Mercosul; coordenar com a RMADS as propostas técnicas elaboradas pelo ISM relativas ao PEAS; propor ao $\mathrm{CMC}$ a adoção de projetos sociais regionais.

Ainda neste novo cenário da agenda integracionista, também é aprovado o "Plano de Ação para a Criação de um Estatuto da Cidadania no Mercosul", por meio da decisão 64/10 do CMC. Esta decisão reconhece a necessidade de se consolidar um conjunto de direitos fundamentais e benefícios em favor dos cidadãos dos Estados Partes do Mercosul. Entre estes benefícios e direitos estão: a implementação de uma política de livre circulação de pessoas na região; a igualdade de direitos e liberdades civis, sociais, culturais e econômicas para os cidadãos dos Estados Partes do Mercosul e a igualdade de condições para acesso ao trabalho, saúde e educação. Posteriormente, este plano de ação foi atualizado por meio da decisão $32 / 17$ do $C M C$, como forma de se adequar à criação de novos foros no Mercosul.

Segundo Martins (2014), a aprovação do Plano Estratégico de Ação Social do Mercosul (PEAS) se constituiu enquanto a principal iniciativa para fortalecer a dimensão social da integração regional. O PEAS foi aprovado primeiramente enquanto documento normativo (decisão 12/11 CMC) "Eixos, diretrizes, e objetivos prioritários do Plano Estratégico de Ação Social do Mercosul", e posteriormente transformado em um documento "mais detalhado" pelo Instituto Social do Mercosul. O PEAS é resultado de um longo processo de desenvolvimento político na região, que teve seu momento mais importante durante a XXX Cúpula de Presidentes do Mercosul em 2006. Nessa reunião, os presidentes dos países do bloco regional solicitaram aos ministros da área social a elaboração de um plano estratégico de ação social:

\begin{abstract}
EI PEAS debería dar cuenta de esta voluntad política de impulso a la elaboración y ejecución de proyectos regionales, desarrollo de estrategias de identificación, intercambio, difusión de mejores prácticas en el área social y de la necesaria articulación entre los distintos ámbitos institucionales del MERCOSUR encargados de la diversa agenda social del bloque (INSTITUTO SOCIAL DO MERCOSUL, 2017, p. 11).
\end{abstract}

O PEAS, em consonância com os Objetivos de Desenvolvimento do Milênio, da ONU, possui dez eixos centrais, cada uma contando com diretrizes e objetivos prioritários: erradicar a fome, a pobreza e combater as desigualdades sociais; garantir os direitos humanos, a assistência humanitária e a igualdade étnica, racial e de gênero; universalizar a saúde pública; universalizar a educação e erradicar o analfabetismo; valorizar e promover a diversidade cultural; garantir a inclusão produtiva; assegurar o acesso ao trabalho decente e aos direitos previdenciários; promover a sustentabilidade ambiental; assegurar o diálogo social e estabelecer mecanismos de cooperação regional para a implementação e financiamento de políticas sociais (MERCOSUL, 2012).

\section{A QUESTÃO PARTICIPATIVA NO MERCOSUL}

No que tange especificamente à incorporação de demandas participativas, foi criado em 2005, o Programa "Somos Mercosul", durante a presidên- 
cia pro tempore do Uruguai (MARTINS, 2014). Este programa tinha como objetivo superar o déficit de participação social existente no bloco regional. Foi uma iniciativa lançada pela presidência pro tempore do Uruguai, com o apoio do então presidente Tabaré Vázquez e dos demais Estados Partes:

Somos Mercosur tuvo como objetivo comprometer a la ciudadanía en el proceso de integración regional, generando espacios para que la sociedad civil y los gobiernos puedan debatir, formular demandas y participar en los procesos decisorios de construcción del Mercosur. La iniciativa correspondió al proceso de creación de una esfera pública regional, fruto de la madurez de la cultura democrática en la región (SILVA; MARTINS, 2016).

Posteriormente, começam a ser realizadas em 2006, as Cúpulas Sociais do Mercosul, criada durante a presidência pro tempore do Brasil (RAMANZINI JÚNIOR, 2015). As Cúpulas Sociais foram espaços de debate político sobre os rumos da integração regional, bem como de discussão e formulação de propostas de políticas públicas, no qual participam representantes de movimentos sociais, os governos e organismos do Mercosul.

Segundo Silva e Martins (2016), as Cúpulas Sociais se inspiraram em experiências de participação social difundidas pela América do Sul. A partir de questionários respondidos por organizações da sociedade civil (OSC) que participaram das Cúpulas Sociais, entre 2006-2015, os autores identificam neste estudo um "desejo de aperfeiçoamento" por parte das OSCs, e não uma percepção de esgotamento do processo. De acordo com Ramanzini Júnior (2015), ao se analisar as declarações finais das treze Cúpulas Sociais realizadas, é possível notar o apoio ao Mercosul e seu aprofundamento, por parte dos atores da sociedade civil que interagem nestes espaços.

Outra importante instância criada para ampliar e fortalecer a dimensão participativa na integração regional é a Unidade de Apoio à Participação Social (UPS), criada em 2010, por meio da decisão 65/10 do CMC. Tal decisão enfatiza a necessidade de fortalecer os mecanismos de participação social no âmbito do Mercosul. A partir da decisão 30/17 do CMC, a UPS passa a integrar a estrutura da Secretaria do Mercosul (SM). Entre suas funções estão, apoiar a organização das Cúpulas Sociais do Mercosul; administrar o financiamento da participação social em eventos e atividades do Mercosul; manter um registro de organizações e movimentos sociais dos Estados Partes; receber, analisar e responder as solicitações de informações apresentadas por representantes de organizações e movimentos sociais dos Estados Partes e coordenar ações, atividades e planos para promover a participação social e implementá-las após aprovação do GMC (MERCOSUL, 2019).

Paralelamente a essas experiências participativas no âmbito regional, experiências nacionais também se desenvolveram, como a criação do Conselho Consultivo da Sociedade Civil, no âmbito do ministério das Relações Exteriores da Argentina e do Conselho Brasileiro do Mercosul Social e Participativo, criado em 2008 (MARTINS, 2014).

No Mercosul, diversos são os órgãos e instâncias que preveem a participação de atores nãoestatais em seus procedimentos institucionais. Os órgãos do Grupo do Mercado Comum (GMC) são os que mais possuem mecanismos participativos, comparativamente. Inclusive, o GMC conta com um órgão considerado modelo institucionalmente quando o assunto é este, a Reunião Especializada da Agricultura Familiar (REAF). De outro lado, o relatório da UPS (2016) identificou apenas uma fraca participação social no Comitê Técnico número 7 de defesa do consumidor, órgão subordinado à Comissão de Comércio do Mercosul (CCM).

O Conselho do Mercado Comum (CMC), órgão decisório máximo, ainda que conte com bons índices de participação social em seus órgãos e instâncias, possui um considerável nível de participação indireta, ou seja, aquela participação que é não prevista na estrutura institucional do órgão, geralmente em seu Regulamento Interno. Apesar disso, tal fato aponta para a pressão exercida por OSC, movimentos sociais e redes no sentido do estabelecimento de um input formal dentro dos distintos órgãos e instâncias que lhe interessam (GOMIDE JUNIOR, 2020).

Segundo Serbin (2012b), o novo regionalismo iniciado nos anos 2000, restringe-se a atores 
políticos tradicionais (governos e partidos políticos), rejeitando a inclusão de atores nãopartidários da sociedade civil, excluindo ou ignorando as redes regionais da sociedade civil. Alguns elementos que se constituem enquanto obstáculos para uma participação social efetiva, segundo o autor, estariam relacionados a uma cultura política elitista que delega e concentra a tomada de decisões em suas mãos (evidência disto é a concentração de poder nas mãos do Executivo no que tange aos temas de política externa e de integração e cooperação internacional, sem passar por instâncias legislativas e por comissões parlamentares ou por mecanismos plebiscitários mais amplos), gerando um evidente déficit democrático somente parcialmente legitimado pelos processos eleitorais; desconfiança desta elite diante da cidadania e suas demandas de participação; regionalismo aberto dos anos 90 convergiu com o marco da governança liberal global, em um contexto de questionamento da autonomia e capacidade do Estado. Dessa forma, os acordos de livre comércio se firmaram em setores tecnocráticos, com pouca ou nenhuma participação dos cidadãos.

Ainda na linha de argumentação do autor, a introdução de uma agenda social no regionalismo não levou a uma nova visão sobre a construção de uma cidadania regional, de caráter social e supranacional. Exemplo disso se refere ao FCES, criado por decisão intergovernamental, que restringiu a participação cidadã a uma agenda préestabelecida focada em uma visão corporativista, pautada pela interação entre governos, sindicatos e empresários. O autor ainda descreve algumas importantes características da sociedade civil latino-americana.

A primeira delas é que a recuperação democrática e as reformas estruturais não levaram a constituição de novos contratos sociais, apoiados em uma institucionalidade e um projeto político nacional. Dessa forma, há uma ausência de um marco institucional sólido e estável, bem como de uma continuidade nos objetivos de Estado. Em segundo lugar, desde a restauração da democracia, a possibilidade de desenvolvimento das organizações cidadãs é condicionada pela ajuda de doadores ex- ternos (recursos da cooperação internacional e de ONGs nórdicas), mais do que por uma abertura do Estado a uma participação institucionalizada. Por fim, a participação cidadã nos processos de integração regional geralmente é percebida como negativa por parte dos governos e organismos intergovernamentais. Dessa forma, os governos somente querem uma cidadania que participa de maneira ordenada e "desde cima" (SERBIN, 2012b).

Em suma, a sociedade civil na América Latina e Caribe se configura no marco de uma matriz sócio-política imposta pelo Estado. Em alguns Estados, este parece ser muito ativo em envolver as organizações da sociedade civil na gestão de alguns setores de políticas públicas, especialmente nos âmbitos locais e municipais, ainda que não gere espaços para sua participação na tomada de decisões, com frequência combinando elementos de cooptação e clientelismo. O autor designa este fenômeno como "cidadanias de baixa intensidade". Dada a amplitude de organizações, redes e movimentos, há também uma falta de articulação nas agendas e objetivos; uma capacidade de influência sobre as políticas públicas limitada; e interlocução com as agências estatais reduzida (SERBIN, 2012b).

Em se tratando especificamente do Mercosul, Alemany (2008) descreve alguns problemas sobre a participação social. Entre estes está a concentração da representação em poucas pessoas; a dificuldade de mobilidade das organizações da sociedade civil; a dificuldade de compreensão da linguagem técnica/tecnocrática de alguns assuntos específicos - por isso há a necessidade de preparação/qualificação dos membros participantes - os regulamentos da maioria dos espaços de participação não estão atualizados ao dinamismo da realidade social e estão pautados por uma visão restritiva de participação; a necessidade de maior transparência e accountability sobre o que é discutido e deliberado; a necessidade de uma política de comunicação formal do Mercosul para informar a sociedade; a necessidade de formação de uma agenda regional por parte da sociedade civil em detrimento de propostas limitadas às realidades nacionais. A última questão está ligada ao fato de que os órgãos de participação possuem mero caráter propositivo/recomendatório: 
Otro desafío es que por lo general no hay visión de proceso ni de largo plazo por parte de los tomadores de decisión en sus negociaciones por lo que se hace muy difícil construir una relación de confianza con los actores sociales. Muchos tomadores de decisión ven a la participación de la sociedad civil como un peso o una oportunidad a instrumentalizar puntualmente. Si se consulta a la ciudadanía después de tomadas las decisiones se puede decir que se está utilizando a la ciudadanía sin integrarla realmente en la toma de decisiones, por lo que cualquier esfuerzo para fortalecer la voz de la ciudadanía debe de integrar una participación a lo largo de todo el proceso de decisiones que no sea ex post (después de tomada la decisión) sino ex ante (antes de decidir) (ALEMANY, p. 126, 2008).

Segundo Alemany e Leandro (2006), a participação da sociedade civil segue sendo um tema abordado de forma precária nos países da região, visto que há vários estágios da participação, em que a informação e a consulta são somente os dois primeiros passos para uma participação efetiva. Ainda segundo os autores, para se analisar as limitações atuais do modelo de participação da sociedade civil deve-se observar os espaços de participação em nível nacional para os temas do Mercosul; os mecanismos de transparência ao nível do Mercosul e os espaços formais de participação no Mercosul e a visão que os próprios atores têm sobre si mesmos. Quanto ao primeiro ponto, nos casos de Argentina e do Brasil, existem espaços de informação e diálogo, mas isso não significa que as organizações da sociedade civil participam da tomada de decisões ou das posições de seus países na agenda regional. Os autores destacam os esforços de consolidação do Conselho Consultivo da Sociedade Civil (CCSC), no âmbito do Ministério de Relações Exteriores da Argentina. Por parte do Brasil, destacase a iniciativa "Encontros com o Mercosul.

\section{CONSIDERAÇÕES FINAIS}

Em suma, podemos ver que, em um primeiro momento, os assuntos comerciais adquirem proeminência no processo de integração regional no Mercosul. No entanto, uma guinada desloca a agenda política da integração regional para assun- tos sociais e políticos, no começo dos anos 2000 . Sendo assim, a dimensão social ganha uma nova e importante tônica na pauta integracionista. Dentro deste amplo leque de assuntos sociais, a participação social figurou como tópico importante por meio da aprovação de inúmeros documentos e normativas, bem como da criação de instâncias e órgãos dedicados a tratar da questão participativa.

Todavia, o "ressurgimento" do Estado frente às políticas de desenvolvimento social, coloca um paradoxo para a democracia participativa: visto que o Estado forte ressurge e se torna ator proeminente na condução integracionista, como podem os atores não-estatais participar com a mesma igualdade de acesso ao processo de formulação e implementação das políticas regionais? Segundo Serbin (2012a), apesar de o cenário otimista em termos de ativismo social, ainda prevalecem dificuldades que se relacionam com a tradição do hiperpresidencialismo na construção e negociação dos regionalismos sul-americanos. Ainda segundo o autor, a questão está em que extensão os novos regionalismos estarão dispostos a superar processos "regionalitários", que estão principalmente relacionados com a falta de canais efetivos para a inclusão de atores sociais na política regional. Em um longo prazo, uma participação efetiva e um empoderamento da sociedade civil ao nível regional dependem de esforços conjuntos de fortalecimento, com uma estrutura democrática, da arquitetura institucional do Estado e das organizações intergovernamentais, assim como o desenvolvimento e o avanço das organizações da sociedade civil, superando suas fraquezas e imperfeições intrínsecas.

Apesar de todas as críticas e sugestões de aprimoramento da participação social no âmbito do Mercosul, podemos perceber que o bloco regional trilhou um relativo curto caminho para a implementação de mecanismos participativos para atores não-estatais. Inúmeros órgãos e instâncias preveem a participação de atores não-estatais em suas estruturas institucionais. E onde não há esta previsão institucional, redes e organizações da sociedade civil pressionam para que ocorra essa abertura democrática, participando informalmente de encontros e eventos ligados ao bloco regional. 
A participação da sociedade civil nos assuntos públicos é um importante indício de democratização das organizações internacionais, o que propicia um paulatino processo de transparência, prestação de contas e accountability frente aos cidadãos.

\section{REFERÊNCIAS}

ALEMANY, Cecilia; LEANDRO, Beatriz. Análisis y propuestas para la participación ciudadana en el Mercosur. Uruguai: Friedrich Ebert Stiftung, 2006.

ALEMANY, Cecilia. La participación ciudadana en el Mercosur: algunas ideas para la reforma institucional pendiente. Pensamiento Proprio, n. 28, p. 113-135, 2008. Disponível em: http://www.cries.org/wp-content/ uploads/2010/05/28.pdf. Acesso em: 17 nov. 2019.

GOMIDE JUNIOR, Natanael. Participação social em organizações internacionais: o caso do Instituto de Políticas Públicas em Direitos Humanos do Mercosul (IPPDH). Dissertação de Mestrado, Universidade Federal de Uberlândia, 2020. Disponível em: https://repositorio.ufu.br/ handle/123456789/ 29099. Acesso em: 23 de Abr. 2020.

GRUGEL, Jean; RIGGIROZZI, Pía. Governance after Neoliberalism in Latin America. New York: Palgrave Macmillan, 2009. DOI: https://doi.org/10.1057/ 9780230622425. Acesso em: 07 mar. 2020.

INSTITUTO SOCIAL DO MERCOSUL. Evaluación de avances en la implementación del Plan Estratégico de Acción Social (PEAS), 2017. Disponível em: http:// www.ismercosur.org/download/evaluacion-deavances-en-la-implementacion-del-plan-estrategicode-accion-social-peas/. Acesso em: 16 nov. 2019.

INSTITUTO SOCIAL DO MERCOSUL. CCMASM - Comisión de Coordenación de Ministerios de Asuntos sociales, 2019. Disponível em: http:// www.ismercosur.org/dimension-social/ccmasm/. Acesso em: 16 nov. 2019.
MALAMUD, Andrés. Latin America Regionalism and EU studies. Journal of European Integration, vol. 32, n. 6, p. 637-657 2010. DOI: https:// doi.org/10.1080/07036337.2010.518720. Acesso em: 07 mar. 2020.

MALAMUD, Andrés. Overlapping regionalism and no integration: conceptual issues and the Latin American experience, EUI Working Paper RSCAS2013/20, 2013. Disponível em: https:// cadmus.eui.eu/bitstream/handle/1814/26336/ RSCAS_2013_20.pdf. Acesso em: 15 nov. 2019.

MARIANO, Karina Pasquariello. A eleição parlamentar no Mercosul. Revista Brasileira de Política Internacional, vol. 54, n.2, p. 138-157, 2011. Disponível em: http://www.scielo.br/pdf/rbpi/v54n2/ v54n2a07.pdf. Acesso em: 15 nov. 2019.

MARTINS, José Renato Vieira; SILVA, Carolina Albuquerque. Políticas sociais e participação social: a constituição de uma esfera pública regional no Mercosul. Boletim de Economia e Política Internacional, n.5, p. 65-71, 2011. Disponível em: http:// repositorio.ipea.gov.br/bitstream/11058/4698/1/ BEPI_n5_politicas.pdf. Acesso em: 16 nov. 2019.

MARTINS, José Renato Vieira. Mercosul: a dimensão social e participativa da integração regional. In: NETO DESIDERÁ, Walter Antonio (Org.). O Brasil e novas dimensões da integração regional. Rio de Janeiro: Ipea, 2014. Disponível em: http:// www.ipea.gov.br/portal/images/stories/PDFs/ livros/livros/livro_brasil_novas_dimensoes.pdf. Acesso em: 16 nov. 2019.

MATTLI, Walter. Comparative regional integration: theoretical developments. Oxford Handbook of the European Union, 2012. DOI: https:// doi.org/10.1093/oxfordhb/9780199546282.013. 0054. Acesso em: 07 mar. 2020.

MERCOSUL. Protocolo de Ouro Preto, 1994. Disponível em: https://www.mercosur.int/pt-br/ documentos-e-normativa/textos-fundacionais. Acesso em: 16 nov. 2019. 
MERCOSUL. Plano Estratégico de Ação Social do Mercosul (PEAS), 2012. Disponível em: http:// www.ismercosur.org/download/peas-plano-estra tegico-de-acao-social-do-mercosul-portugues/.

Acesso em: 16 nov. 2019.

MERCOSUL. Unidade de Apoio à Participação Social, 2019. Disponível em: https:// www.mercosur.int/pt-br/quem-somos/secretaria/ ups/. Acesso em: 16 nov. 2019.

NATERA, Miguel Ángel Contreras. Democracia, Ciudadanía y Políticas Sociales. Desafíos del Mercosur Social. Pensamiento Proprio, vol. 43, p. 155-172, 2016. Disponível em: http://www.cries.org/wpcontent/uploads/2016/09/010-contreras.pdf. Acesso em: 16 nov. 2019.

RAMANZINI JÚNIOR, Haroldo. Demandas sociais, política externa e regionalismo. Boletim de Economia e Política Internacional, n.20, p. 5-19, 2015. Disponível em: http://repositorio.ipea.gov.br/ bitstream/11058/5901/1/BEPI_n20_demandas.pdf. Acesso em: 16 nov. 2019.

RIGGIROZZI, Pía; TUSSIE, Diana. The Rise of Posthegemonic Regionalism: the Case of Latin America. London: Springer, 2012. DOI: https:// doi.org/10.1007/978-94-007-2694-9. Acesso em: 07 mar. 2020.

RIGGIROZZI, Pía. Re-territorializando consensos: hacia un regionalismo post-hegemónico en América Latina. In: SERBIN, Andrés; MARTINEZ, Laneydi; RAMANZINI JÚNIOR, Haroldo. El regionalismo "post-liberal" en América Latina y el Caribe: nuevos actores, nuevos temas, nuevos desafíos. Buenos Aires: CRIES, 2012. Disponível em: https:// sites.usp.br/prolam/wp-content/uploads/sites/ 35/2019/05/CCD23_2012-Anuario.pdf. Acesso em: 16 nov. 2019.

SANAHUJA, José Antonio. La construcción de una región: Suramérica y el regionalismo posliberal. In:
CIENFUEGOS, Manuel; SANAHUJA, José Antonio (Org.). Una región en construcción: UNASUR y la integración en América del Sur. Barcelona: Fundación CIDOB, 2010.

SERBIN, Andrés. New Regionalism and Civil Society: Bridging the Democratic Gap? In: RIGGIROZZI, Pía; TUSSIE, Diana. The Rise of Post-hegemonic Regionalism: The Case of Latin America. London: Springer, cap. 8, p. 147-165, 2012a. DOI: https:// doi.org/10.1007/978-94-007-2694-9_8. Acesso em: 07 mar. 2020.

SERBIN, Andrés. Déficit democrático y participación ciudadana en el marco del regionalismo postliberal. In: SERBIN, Andrés; MARTíNEZ, Laneydi; RAMANZINI JÚNIOR, Haroldo. El regionalismo "post-liberal" en América Latina y el Caribe: nuevos actores, nuevos temas, nuevos desafíos. Buenos Aires: CRIES, 2012b. Disponível em: https:// sites.usp.br/prolam/wp-content/uploads/sites/ 35/2019/05/CCD23_2012-Anuario.pdf. Acesso em: 16 nov. 2019.

SERBIN, Andrés. Atuando sozinho? Governos, sociedade civil e regionalismo na América do Sul. Lua Nova, n. 90, p. 297-327, 2013. DOI: https:// doi.org/10.1590/S0102-64452013000300011. Acesso em: 07 mar. 2020.

SILVA, Carolina Albuquerque; MARTINS, José Renato Vieira. Las Cumbres sociales del Mercosur I: historia y acervo. UPS, 2016. Disponível em: https:// www.mercosur.int/documento/las-cumbressociales-del-mercosur/. Acesso em: 16 nov. 2019.

VIGEVANI, Tullo. Globalização e regionalização do Mercosul: a intervenção dos sindicatos no processo de integração. Caderno CEDEC, n. 57, p. 1-57, 1996. Disponível em: http://www.cedec.org.br/globalizacao-eregionalizacao-do-mercosul-a-inter vencaodos-sindicatos-no-processo-de-integracao-. Acesso em: 16 nov. 2019. 